\title{
Unraveling the neurotoxicity of titanium dioxide nanoparticles: focusing on molecular mechanisms
}

\author{
Bin Song ${ }^{1,2}$, Yanli Zhang ${ }^{2}$, Jia Liu ${ }^{2}$, Xiaoli Feng ${ }^{2}$, Ting Zhou ${ }^{1}$ and Longquan Shao ${ }^{*}, \S$
}

\author{
Review \\ Address: \\ ${ }^{1}$ Guizhou Provincial People's Hospital, Guiyang 550002, China and \\ ${ }^{2}$ Nanfang Hospital, Southern Medical University, Guangzhou 510515, \\ China \\ Email: \\ Longquan Shao* - shaolongquan@smu.edu.cn \\ * Corresponding author \\ $\S$ Tel: +86 15989283921 \\ Keywords: \\ autophagy; brain; DNA methylation; neurotoxicity; titanium dioxide \\ nanoparticles
}

Beilstein J. Nanotechnol. 2016, 7, 645-654. doi:10.3762/bjnano.7.57

Received: 29 January 2016

Accepted: 21 April 2016

Published: 29 April 2016

Associate Editor: M. Stenzel

(C) 2016 Song et al; licensee Beilstein-Institut. License and terms: see end of document.

\begin{abstract}
Titanium dioxide nanoparticles $\left(\mathrm{TiO}_{2} \mathrm{NPs}\right)$ possess unique characteristics and are widely used in many fields. Numerous in vivo studies, exposing experimental animals to these NPs through systematic administration, have suggested that $\mathrm{TiO}_{2} \mathrm{NPs}_{\text {can }}$ accumulate in the brain and induce brain dysfunction. Nevertheless, the exact mechanisms underlying the neurotoxicity of $\mathrm{TiO}_{2} \mathrm{NPs}$ remain unclear. However, we have concluded from previous studies that these mechanisms mainly consist of oxidative stress (OS), apoptosis, inflammatory response, genotoxicity, and direct impairment of cell components. Meanwhile, other factors such as disturbed distributions of trace elements, disrupted signaling pathways, dysregulated neurotransmitters and synaptic plasticity have also been shown to contribute to neurotoxicity of $\mathrm{TiO}_{2} \mathrm{NPs}$. Recently, studies on autophagy and DNA methylation have shed some light on possible mechanisms of nanotoxicity. Therefore, we offer a new perspective that autophagy and DNA methylation could contribute to neurotoxicity of $\mathrm{TiO}_{2} \mathrm{NPs}$. Undoubtedly, more studies are needed to test this idea in the future. In short, to fully understand the health threats posed by $\mathrm{TiO}_{2} \mathrm{NPs}$ and to improve the bio-safety of $\mathrm{TiO}_{2} \mathrm{NPs}$-based products, the neurotoxicity of $\mathrm{TiO}_{2} \mathrm{NPs}$ must be investigated comprehensively through studying every possible molecular mechanism.
\end{abstract}

\section{Introduction}

Titanium dioxide nanoparticles, smaller than $1 \mu \mathrm{m}$ in at least one dimension, possess specific physico-chemical characteristics [1] including antibacterial, ultraviolet-absorbing, photocatalytic, and self-cleaning properties [2]. Thus, $\mathrm{TiO}_{2} \mathrm{NPs}$ are widely used in cosmetics, sun screens, ceramics, paints, pack- aging, lithium batteries, the food industry, and in medical applications [3]. However, the rapid development of nanotechnology and widespread applications of products containing $\mathrm{TiO}_{2}$ NPs have increased the risk of exposure. Therefore, numerous in vivo and in vitro studies have been performed to scrutinize 
the potential toxic properties of $\mathrm{TiO}_{2} \mathrm{NPs}$ in recent years [4]. Research has demonstrated that $\mathrm{TiO}_{2}$ NPs can be detected in the main organs of experimental animals $[5,6]$ and in exhaled breath condensate of exposed workers [7]. This accumulation can in turn damage affected organs and induce dysfunction.

The brain is of particular interest, as it is unable to regenerate from damage. Consequently, the neurotoxicity of nanomaterials should receive considerable attention. For this reason, we discussed the application and bio-distribution of $\mathrm{TiO}_{2} \mathrm{NPs}$, pathways through which they are translocated into the brain, harmful effects induced by them on the brain, and factors that can regulate their neurotoxic properties in our recent review [8]. However, the molecular mechanisms underlying this neurotoxicity were not discussed in detail. Therefore, in this review, we aim to discuss all previously described molecular mechanisms underlying the neurotoxicity of $\mathrm{TiO}_{2}$ NPs by summarizing published articles. From our research, we conclude that the major mechanisms are oxidative stress (OS), inflammatory responses, apoptosis, genotoxicity, and direct impairment of cell components. However, it appears that $\mathrm{TiO}_{2} \mathrm{NPs}$-induced neurotoxicity results from multiple mechanisms. Furthermore, other minor mechanisms exist and include disturbed distributions of trace elements, disrupted signaling pathways, dysregulated neurotransmitters and synaptic plasticity (Table 1 and Table 2).
Recent studies have reported that autophagy [9] and DNA methylation $[10,11]$ are also involved in nanotoxicity (Table 3). Therefore, we hypothesized that autophagy and DNA methylation can be included as major mechanisms underlying the neurotoxicity of $\mathrm{TiO}_{2}$ NPs. Autophagy (from Greek, "auto" meaning oneself and "phagy" meaning to eat) was identified as a unique adaptation of cells to starvation and involves the cellular degradative pathway through which cytoplasmic cargo is delivered to the lysosome. Autophagy also acts as a dynamic recycling system wherein new building blocks and energy, for cellular renovation and homeostasis, are produced [12].

The literal meaning of "epigenetics" is "outside conventional genetics", which is defined as all heritable alternations in gene expression. These stable alternations are not caused by changes to DNA sequence itself, but instead arise during development and cell proliferation $[13,14]$. DNA methylation is the one of the most extensively studied epigenetic mechanisms. Whether $\mathrm{TiO}_{2}$ NPs are able to induce neurotoxicity through altering autophagy or DNA methylation status in brain remains uncertain. Further studies are required to further verify their role in neurotoxicity induced by $\mathrm{TiO}_{2}$ NPs. To fully understand threats to the brain posed by $\mathrm{TiO}_{2} \mathrm{NPs}$, and improve the bio-safety of $\mathrm{TiO}_{2}$ NPs-based products, neurotoxicity of these compounds must be investigated comprehensively.

\begin{tabular}{|c|c|c|c|}
\hline objects & administration route & mechanisms of neurotoxicity & references \\
\hline rats & intravenous injection & $\begin{array}{l}\text { indirect mechanism (induced by cytokines and } \\
\text { pro-inflammatory mediators in systemic circulation) }\end{array}$ & [6] \\
\hline mice & nasal administration & inflammatory response (over-proliferation in glia cells) & [29] \\
\hline rats & intravenous injection & OS and angiotensin system & {$[22]$} \\
\hline rats & intravenous injection & multiple (OS, inflammatory response and DNA damage) & [55] \\
\hline mice & oral administration & OS (ROS and anti-oxidant enzymes disturbed) & [23] \\
\hline mice & inhalation & $\mathrm{OS}\left(\mathrm{H}_{2} \mathrm{O}_{2}\right.$ and MDA elevated $)$ & {$[24]$} \\
\hline mice & oral administration & other mechanisms & {$[57]$} \\
\hline mice & intranasal administration & inflammatory response & {$[30]$} \\
\hline pregnant rats & subcutaneous injection & OS & [26] \\
\hline pregnant rats & oral administration & other mechanisms (cell proliferation inhibited) & {$[58]$} \\
\hline pregnant mice & subcutaneous injection & other mechanisms (disrupted dopamine systems) & {$[59,60]$} \\
\hline pregnant mice & subcutaneous injection & multiple mechanisms (apoptosis, OS and neurotransmitters) & {$[50]$} \\
\hline mice & nasal instillation & OS & {$[21]$} \\
\hline mice & nasal instillation & multiple mechanisms (OS and inflammatory response) & [49] \\
\hline mice & delivery in abdominal cavity & OS & {$[25]$} \\
\hline mice & intragastric administration & $\begin{array}{l}\text { other mechanisms (disturbed distributions of trace elements, } \\
\text { enzymes and neurotransmitters) }\end{array}$ & [61] \\
\hline mice & intragastric administration & multiple mechanisms (apoptosis and OS) & {$[54]$} \\
\hline mice & intranasal administration & P38-Nrf-2-mediated OS & [31] \\
\hline neonatal rats & lactation exposure orally & disturbed synaptic plasticity & [62] \\
\hline rats & trachea administration & inflammatory response & [32] \\
\hline mice & injection in abdominal cavity & genotoxicity induced by OS & [43] \\
\hline
\end{tabular}




\begin{tabular}{|c|c|c|}
\hline cell types & mechanisms of neurotoxicity & references \\
\hline BV2 & OS (ROS, $\mathrm{H}_{2} \mathrm{O}_{2}$ elevated) & {$[19,20]$} \\
\hline primary hippocampal neurons & $\begin{array}{l}\text { multiple mechanisms (disrupted glutamate metabolism and dysregulated levels of } \\
\text { NMDARs) }\end{array}$ & {$[56]$} \\
\hline primary hippocampal neurons & apoptosis mediated by mitochondria- and endoplasmic reticulum-pathways & [35] \\
\hline primary astrocytes & direct impairment of mitochondria and ROS & {$[38]$} \\
\hline D384 and SH-SY5Y & direct impairment of mitochondria and cell membrane & [39] \\
\hline SH-SY5Y & direct impairment of microtubules and cell morphology & {$[40]$} \\
\hline SH-SY5Y & multiple mechanisms (changed cell cycle, apoptosis, and DNA damage) & {$[53]$} \\
\hline C6 and U373 & OS and impairment of mitochondria & {$[48]$} \\
\hline C6 and U373 & $\begin{array}{l}\text { multiple mechanisms (inhibited cell proliferation, morphological change and } \\
\text { apoptosis) }\end{array}$ & {$[52]$} \\
\hline N9 & apoptosis & {$[36]$} \\
\hline U87 & apoptosis & {$[37]$} \\
\hline PC12 & multiple mechanisms (OS and apoptosis) & {$[51]$} \\
\hline PC12 & other mechanisms (signaling pathway activated and arrested cell cycle) & [63] \\
\hline
\end{tabular}

\begin{tabular}{lll}
$\begin{array}{l}\text { Table 3: Autophagy and DNA methylation in non-neuronal cells in- } \\
\text { duced by } \mathrm{TiO}_{2} \text { NPs. }\end{array}$ & mechanisms & references \\
cell type & autophagy & {$[74]$} \\
\hline normal lung cell & autophagy & {$[75]$} \\
primary human keratinocytes & DNA methylation & {$[100]$}
\end{tabular}

\section{Review \\ Established mechanisms underlying the neurotoxicity of $\mathrm{TiO}_{2} \mathrm{NPs}$}

To fully understand potential health threats posed by $\mathrm{TiO}_{2} \mathrm{NPs}$, we summarized recent articles about the neurotoxicity of $\mathrm{TiO}_{2}$ NPs in our recently published review. We found that after rats or mice were exposed to $\mathrm{TiO}_{2} \mathrm{NPs}$ via several administration routes (e.g., nasal instillation, subcutaneous injection and oral exposure), NPs can be absorbed and translocated into the brain mainly through the blood-brain barrier (BBB) or the nose-tobrain pathway, which bypasses the BBB. Given that $\mathrm{TiO}_{2} \mathrm{NPs}$ were able to pass the placental barrier and accumulate in the fetal brain by penetrating the undeveloped $\mathrm{BBB}, \mathrm{TiO}_{2} \mathrm{NPs}$ exposure during gestation can impair fetal brain development. Based on the limited excretion rate from brain, even low-dose exposure to $\mathrm{TiO}_{2}$ NPs can lead to gradual accumulation over a long period of time. This accumulation can in turn affect brain development, impair brain function, and can even result in disabilities in learning and memory assessed by poor performance in behavioral tests.

As stated previously, the major mechanisms of $\mathrm{TiO}_{2} \mathrm{NPs}-\mathrm{in}$ duced neurotoxicity are oxidative stress (OS), inflammatory responses, apoptosis, genotoxicity, and direct impairment of cell components. However, in most situations, neurotoxicity occurs through multiple mechanisms. Furthermore, other minor mechanisms include disturbed distributions of trace elements, disrupted signaling pathways, dysregulated neurotransmitters, and synaptic plasticity.

\section{Oxidative stress mechanism}

Oxidative stress (OS) is defined as the production of reactive oxygen species (ROS) or/and reactive nitrogen species (RNS) at a rate much high than the elimination rate after the organism encounters harmful stimulus. OS can injure tissues and organs, and is often associated with diseases and aging. Meanwhile, oxidative stress, caused by NPs, is the most important and widely accepted mechanism of nano-neurotoxicity. ROS, such as superoxide, hydrogen peroxide, and hydroxyl radicals, are natural products of the regular oxygen metabolism $[15,16]$. However, these free radicals can interact within biological systems, resulting in oxidative damage to the organism. These harmful effects can be counteracted by biological antioxidants, including superoxide dismutase (SOD), catalase (CAT), glutathione peroxidase (GSH-Px), the expression of which needs to be coordinately regulated with the onset of OS $[17,18]$. If this balance is interrupted, levels of NPs-activated OS surpass the capacity of the biological antioxidants, potentially resulting in toxic oxidative stress. As a result, central nervous system (CNS) dysfunctions might ultimately be induced.

Long et al. $[19,20]$ first revealed in their in vitro studies that $\mathrm{TiO}_{2}$ NPs can induce dose- and time-dependent elevations in $\mathrm{H}_{2} \mathrm{O}_{2}$ levels in BV2 cells (an immortalized brain microglia cell line). BV2 internalized $\mathrm{TiO}_{2} \mathrm{NPs}$ and subsequently swollen mitochondria were detected by transmission electron microscopy (TEM), indicating that the function of the mitochondria was 
disrupted. Mitochondria are the sites of aerobic respiration, and generally are the major energy production center in eukaryotes. Dysfunction of mitochondria would thus influence energy metabolism.

Many in vivo studies have also verified the role of $\mathrm{OS}$ in $\mathrm{TiO}_{2}$ NPs-induced neurotoxicity. Wang et al. [21] found that nasal instillation of $\mathrm{TiO}_{2} \mathrm{NPs}$ can lead to histopathological changes in the mouse brain. At the same time, the activity of superoxide dismutase (SOD) was inhibited, methane dicarboxylic aldehyde (MDA) levels were increased, and acetylcholin esterase (AChE) activity was enhanced in brain tissues. These changes indicated that OS was involved in neurological lesions induced by $\mathrm{TiO}_{2}$ NPs. In further studies, Krawczynska et al. [22] injected rats with $\mathrm{TiO}_{2}$ NPs intravenously. Twenty-eight days after injection, the level of aromatase was reduced and glutathione peroxidase and reductase activities were suppressed, implying that the regulation of oxidative stress in the brain was disturbed. In this study, the angiotensin system was disrupted as well. In addition, after Shrivastava et al. [23] treated male mice with $\mathrm{TiO}_{2} \mathrm{NPs}$ through oral administration for 21 days, ROS increased, and the activities of anti-oxidant enzymes (such as SOD, and CAT, among others) were affected in the brain tissues. These changes were associated with neurotoxicity of $\mathrm{NPs} \mathrm{TiO}_{2} \mathrm{NPs}$ were also shown to induce elevated levels of $\mathrm{H}_{2} \mathrm{O}_{2}$ and MDA in the brain after mice were put in chambers with a steady flow of $\mathrm{TiO}_{2} \mathrm{NPs}$ (mimicking inhalation exposure), for $8 \mathrm{~h}$ per day, for 3 weeks [24]. Ma et al. [25] found that exposure to $\mathrm{TiO}_{2}$ NPs, through delivery in the abdominal cavity, can lead to histopathological changes in mouse brain. This was accompanied by elevated levels of ROS, MDA, constitutive nitric oxide synthase (cNOS), induced nitric oxide synthase (iNOS), and nitric oxide (NO), and inhibited activities of SOD, CAT, ascorbate peroxidase (APX), glutathione peroxidase (GSH-Px), total antioxidant capacity (T-AOC), and AChE, as well as through reduced ratios of ascorbic acid (AsA) to oxidized AsA (DAsA) and glutathione (GSH) to oxidized glutathione (GSSG). These changes implied that OS, induced by $\mathrm{TiO}_{2} \mathrm{NPs}$, mainly contributed to neurotoxicity. In addition, maternal exposure to $\mathrm{TiO}_{2} \mathrm{NPs}$ was also shown to affect the OS status in the fetal brain. After pregnant rats were administrated with $\mathrm{TiO}_{2}$ NPs through subcutaneous injection, neonates showed down-regulated expression of CAT, GSH-Px, T-AOC, and an increase in both MDA expression and oxidative impairment of the DNA. When neonates matured, their performance was poor in behavioral tests (novel object recognition test, forced swim test, and sucrose preference test) [26].

\section{Inflammatory response}

Inflammatory response induced by $\mathrm{TiO}_{2} \mathrm{NPs}$ is another major mechanism of neurotoxicity. When $\mathrm{TiO}_{2} \mathrm{NPs}$ are transported to the brain, they interact with neurons and glial cells. Microglia are considered to be innate immune cells residing in brain. Once they are activated by exogenous substances, pro-inflammatory cytokines are released to induce neuro-inflammation [27,28]. $\mathrm{TiO}_{2}$ NPs acting as a stimulus were able to activate microglia cells. Su et al. [29] treated mice with $\mathrm{TiO}_{2}$ NPs by nasal administration for nine months, after which the glial cells showed over-proliferation and tissue necrosis was found in hippocampal area. Meanwhile, the expression of genes associated with neurotrophin signaling pathways, such as nerve growth factor (NGF) and brain-derived neurotrophic factor (BDNF), were altered in the hippocampal area, indicating that these genes were related to the neuro-inflammatory responses induced by $\mathrm{TiO}_{2}$ NPs. After mice were exposed to $\mathrm{TiO}_{2}$ NPs through intranasal administration for 90 days, expression of toll-like re-

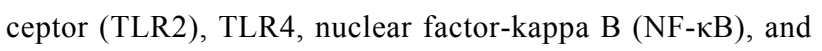
tumor necrosis factor- $\alpha(\mathrm{TNF}-\alpha)$ in the mouse hippocampus was promoted. At the same time, histopathological changes were observed in the hippocampus; over-proliferation of glial cells, impaired nuclei, and cellular degeneration were observed, all of which contributed to neuro-inflammation. In addition, locomotor activity in these mice was affected. These changes suggested that inflammatory responses play a role in $\mathrm{TiO}_{2} \mathrm{NPs}$-induced neurotoxicity [30]. Ze et al. [31] treated mice with $\mathrm{TiO}_{2}$ NPs by intranasal administration for 90 days to determine if the p38-nuclear factor-E2-related factor-2 (p38-Nrf-2) signaling pathway was implicated in OS. Data showed that the expression of p38, Jun N-terminal kinase (JNK), NF- $\kappa B, N r f-2$, and heme oxygenase (HO-1) was promoted in the brain of $\mathrm{TiO}_{2}$ NPs-treated groups. Simultaneously, levels of $\mathrm{O}^{2-}, \mathrm{H}_{2} \mathrm{O}_{2}$, MDA, carbonyl, and 8-hydroxy-2'-deoxyguanosine (8-OHdG) were also enhanced. These findings indicated that the activated p38-Nrf-2 signaling pathway could induce excessive OS, leading to over-proliferation of spongiocytes and hematencephalon. Exposure to $\mathrm{TiO}_{2}$ NPs through tracheal administration has also been shown to induce the expression of interleukin-1 $\beta$ (IL$1 \beta)$, TNF- $\alpha$, and IL-10 in the brain. Herein, an impairment of the the blood-brain barrier and damage of astrocytes was observed [32].

\section{Apoptosis dysfunction}

Apoptosis, also called programmed cell death, is defined as the genetically determined elimination of cells. The activation of caspase plays a pivotal role in apoptosis. Human health and disease can be modulated by apoptosis [33,34]. Sheng et al. [35] found that $\mathrm{TiO}_{2}$ NPs induced apoptosis in primary hippocampal neurons. Elevated levels of $\mathrm{Ca}^{2+}$, cytochrome c, Bax, caspase-3, and caspase-12, as well as a reduction in mitochondrial membrane potential (MMP) and blc-2 levels, indicated that mitochondria- and endoplasmic reticulum-mediated signaling pathways were involved in the apoptotic process. $\mathrm{TiO}_{2} \mathrm{NPs}$ were 
also shown to decrease cell viability by inducing apoptosis in the microglia N9 [36] and human astrocytes-like astrocytoma U87 cell lines [37].

\section{Direct toxic effects on cell structures}

Cell components, such as the cell membrane and mitochondria, can be targets of $\mathrm{TiO}_{2} \mathrm{NPs}$. $\mathrm{TiO}_{2} \mathrm{NPs}$ can decrease cell viability of primary rat astrocytes. Herein, the mitochondrial morphology was changed and mitochondrial membrane potential (MMP) was reduced, suggesting mitochondrial impairment. At the same time, glutamate uptake was down-regulated, and ROS was promoted [38]. Coccini et al. [39] found that when D384 (human glial cell line) and SH-SY5Y (human neuronal cell line) cells were treated with $\mathrm{TiO}_{2}$ NPs, mitochondrial dysfunction, impaired cell membrane, and changes in cell morphology were detected. Mao et al. [40] discovered that a dose of $\mathrm{TiO}_{2}$ NPs, having no effect on viability in SH-SY5Y cells could cause changes in cell morphology and disruptions to the microtubule structure, both of which are associated with neurotoxicity. In addition, Ben Younes et al. [41] treated rats with $\mathrm{TiO}_{2} \mathrm{NPs}$ through intraperitoneal injection. After which, rats exhibited altered emotional behavior in a plus maze test; however, histopathological examination demonstrated no significant differences between treated and control groups. The study failed to discuss other mechanisms associated with nanoneurotoxicity.

\section{Genotoxicity}

Genotoxicity is simply defined as the induction of DNA damage, in a direct or indirect manner, caused by substances such as benzopyrene in cigarettes or some chemotherapeutic drugs. In vivo and in vitro studies typically measure genotoxicity using the comet assay, the micronucleus test, the Ames test, and the chromosome aberration assay [42]. Golbamaki et al. [42] summarized genotoxicity data of NPs from available studies in their review, concluding that NPs can induce genotoxicity, and the mechanisms through which this occurs can be divided into direct primary genotoxicity, indirect primary genotoxicity, and secondary genotoxicity (for a comprehensive review, see Golbamaki et al. [42]). $\mathrm{TiO}_{2} \mathrm{NPs}$, like other types of engineered NPs, can induce genotoxicity. However, Golbamaki et al. did not report on $\mathrm{TiO}_{2}$ NPs-induced genotoxicity in the brain or in brain cells. Obviously, the relationship between neurotoxicity of $\mathrm{TiO}_{2} \mathrm{NPs}$ and genotoxicity should be investigated comprehensively. Recently, El-Ghor et al. [43] determined that $\mathrm{TiO}_{2}$ NPs could cause DNA damage in the mouse brain. This genotoxicity could be alleviated by co-treatment with chlorophyllin (CHL). CHL is a free radical scavenger and is able to reduce the harmful effects of OS $[44,45]$. These findings suggest that oxidative stress induced by $\mathrm{TiO}_{2} \mathrm{NPs}$ can cause genotoxicity to the brain.

\section{Multiple mechanisms}

Usually, activation of glia cells and mitochondrial injury are able to initiate excessive ROS production $[27,46]$. Meanwhile, ROS can lead to apoptosis and genotoxicity $[43,47]$. Therefore, the above-mentioned mechanisms, including OS, apoptosis, inflammatory responses, genotoxicity, and direct impairments on cell components may be jointly implicated in $\mathrm{TiO}_{2}$ NPs-induced neurotoxicity. OS (which promotes ROS and affects the activities of SOD, GPx, CAT) and mitochondrial impairments were observed in $\mathrm{TiO}_{2}$ NPs-treated glial cells (C6 and U373) [48]. After glial cells are damaged by $\mathrm{TiO}_{2} \mathrm{NPs}$, inflammatory responses would presumably occur. This might exacerbate brain damage further. Wang et al. [49] found that intranasal instillation of $\mathrm{TiO}_{2}$ NPs can induce histopathological changes in the mouse brain, in which OS (MDA increases) and inflammatory responses (elevated expressions of TNF- $\alpha$ and IL-1 $\beta$ ) were involved. Shimizu et al. [50] analyzed the brains of mouse offspring by cDNA microarray and found that prenatal exposure to $\mathrm{TiO}_{2}$ NPs could alter the expression of neurotransmitter genes as well as genes associated with apoptosis, OS, and psychiatric disorders. $\mathrm{TiO}_{2}$ NPs decreased cell viability in PC12 cells in a dose- and time-dependent manner by increasing the level of ROS and proportion of apoptotic cells. Pretreating PC12 with a ROS scavenger could alleviate these harmful effects induced by $\mathrm{TiO}_{2}$ NPs [51]. In addition, an inhibition in cell proliferation, altered cell morphology (assessed by decreased F-actin), and apoptosis could be induced by $\mathrm{TiO}_{2} \mathrm{NPs}$ in $\mathrm{C} 6$ and $\mathrm{U} 373$ cells. $\mathrm{TiO}_{2}$ NPs were also internalized by $\mathrm{C} 6$ and U373 cells [52]. Valdiglesias et al. [53] found that NPs were internalized by SH-SY5Y neuronal cells exposed to $\mathrm{TiO}_{2}$ NPs, which coincided with alterations in the cell cycle and an elevation in the proportion of apoptotic cells. Damage of the DNA was induced and NO oxidative stress was observed in these experimental groups. The treatment of mice with $\mathrm{TiO}_{2}$ NPs by intragastric administration resulted in an impairment of their spatial recognition memory. This impairment was mainly due to elevated expression of caspase-3 and caspase-9, Bax, and cytochrome c, and suppressed Bcl-2, in the hippocampal area. Meanwhile, the ROS levels were enhanced, and the activities of antioxidant enzymes such as SOD, CAT, ascorbate peroxidase (Apx), and GSH-Px were inhibited. In addition, the ratios of AsA to DAsA and GSH to GSSG were decreased. These changes suggested that apoptosis and OS were involved in $\mathrm{TiO}_{2}$ NPs-induced neurotoxicity [54]. Meena et al. [55] found that after rats were administrated $\mathrm{TiO}_{2}$ NPs by intravenous injection, once a week for four weeks, the ROS in the brain were significantly enhanced. This elevation of ROS promoted an inflammatory responses and led to decreased activities of SOD and GPx, elevated MDA and DNA damage, as well as an increased proportion of apoptotic cells. 


\section{Minor mechanisms}

In addition to major mechanisms of $\mathrm{TiO}_{2} \mathrm{NPs}$-induced neurotoxicity, other minor mechanisms exist. Disdier et al. [6] discovered that after rats received $\mathrm{TiO} 2$ NPs through intravenous injection, neuro-inflammation was not directly induced by $\mathrm{Ti}$ accumulation in the brain, but instead was indirectly stimulated by cytokines or pro-inflammatory mediators in systemic circulation. Hong et al. [56] demonstrated that the decreased cell viability of primary hippocampal neurons was associated with inhibited dendritic growth, disrupted glutamate metabolism, dysregulated levels of $N$-methyl-D-aspartate receptors (NMDA receptors), increased $\mathrm{Ca}^{2+}$ levels and voltage of $\mathrm{I}_{\mathrm{k}}$ in cells, and reduced activity of ATPase. However, additional experiments were needed to further discuss how each of these parameters contributed to neurotoxicity. Ze et al. [57] found that after mice were treated with $\mathrm{TiO}_{2}$ NPs by oral exposure, histopathological changes in the hippocampus were occurred. Meanwhile, affected neuron ultrastructures, such as swollen mitochondria and impaired nuclear membrane were detected. Longterm potentiation (LTP) in the hippocampus was reduced and the expressions of NMDA receptors were down-regulated as well. These changes contributed to impaired spatial memory. Prenatal exposure to $\mathrm{TiO}_{2}$ NPs was also shown to result in decreased cell proliferation in the hippocampus of rat offspring, which was associated with poor performance in the Morris water maze test and passive avoidance test [58]. Maternal exposure to $\mathrm{TiO}_{2}$ NPs can also affect the production of dopamine and its metabolites, as determined by high performance liquid chromatography (HPLC) [59], and alter gene expression related to dopamine systems, as measured by DNA microarray in neonatal mouse brain [60]. Mice performed poorly in the Y-maze test after a $60 \mathrm{~d}$ exposure to $\mathrm{TiO}_{2} \mathrm{NPs}$, and histopathological changes were observed in brain. Meanwhile, the intracellular content of trace elements $(\mathrm{Ca}, \mathrm{Mg}, \mathrm{Na}, \mathrm{K}, \mathrm{Zn}$, and $\mathrm{Fe}$ ) was disturbed. The activities of $\mathrm{Na}^{+} / \mathrm{K}^{+}$-ATPase, $\mathrm{Ca}^{2+}$-ATPase, and $\mathrm{Ca}^{2+} / \mathrm{Mg}^{2+}$-ATPase also decreased, and the levels of neurotransmitters, including acetyl choline (Ach), glutamic acid (Glu), and NO were elevated. The expression of monoamine neurotransmitters consisting of norepinephrine (NE), dopamine (DA), dihydroxyphenylacetic acid (DOPAC), 5-hydroxytryptamine (5-HT), and 5-hydroxyindoleacetic acid (5-HIAA) was down-regulated. These changes impaired spatial recognition memory [61]. When mother rats were exposed to $\mathrm{TiO}_{2} \mathrm{NPs}$ during the lactation period, their offspring exhibited dysregulated synaptic plasticity that included the input/output (I/O) function, paired-pulse reaction, and long-term potentiation in the hippocampal zone. These developmental changes in the hippocampus could impair learning ability and memory [62]. $\mathrm{TiO}_{2}$ NPs also decreased PC12 viability through activation of JNK- and p53-mediated pathways, which disrupted cell cycle, leading to apoptosis and excessive ROS [63].

\section{Uncertain mechanisms underlying $\mathrm{TiO}_{2}$ NPs-induced neurotoxicity Autophagy}

Autophagy can be divided into three types, 1) microautophagy, 2) macroautophagy, and 3) identified-chaperone-mediated autophagy. It is believed that macroautophagy (referred to as autophagy) is the main degradative pathway among these subtypes of autophagy $[64,65]$. Autophagy also acts as a dynamic recycling system in which new building blocks, and energy for cellular renovation and homeostasis, are produced [12]. However, excessive autophagy can contribute to cell death. Autophagy has been determined to be a potential mechanism of nanotoxicity $[9,66]$. However, few studies have described the relationship between neurotoxicity and nanomaterials. It was revealed that gold nanoparticles can increase the levels of autophagyrelated proteins in human lung fibroblasts (MRC-5), concomitant with excessive MDA production [67]. After lung epithelial cancer cells (A549) were exposed to iron oxide nanoparticles, ROS production, mitochondrial impairments and autophagy were detected [68]. Autophagy in human peripheral blood monocytes can be induced by cerium dioxide nanoparticles [69]. In addition, copper oxide NPs [70], silica NPs [71], zinc oxide NPs [72], and silver NPs [73] were shown to induce autophagy in in vitro studies. $\mathrm{TiO}_{2} \mathrm{NPs}$ were also capable of inducing autophagy. Studies showed that $\mathrm{TiO}_{2} \mathrm{NPs}$ could induce autophagy in normal lung cells [74] and in primary human keratinocytes [75]. Based on the studies illustrated above, we hypothesize that $\mathrm{TiO}_{2}$ NPs can induce autophagy dysfunctions in brain tissues and cells. Therefore, autophagy could be a potential mechanism underlying $\mathrm{TiO}_{2}$ NPs-induced neurotoxicity. However, more studies are needed to further investigate the relationship between brain damage and $\mathrm{TiO}_{2}$ NPs-mediated autophagy dysfunction.

\section{Epigenetics}

Another potential mechanism of $\mathrm{TiO}_{2} \mathrm{NPs}$ is epigenetic regulations. Epigenetic changes were reported to be implicated in nanotoxicity $[10,11]$. Epigenetics refers to all heritable alternations in gene expression not caused through changes to the DNA sequence itself, but rather arise during development and cell proliferation $[13,14]$. In other words, the epigenetics represents the interactions between gene expression and environmental factors, and the relationship between genes, which were modulated during development and adult life [76]. In most situations, epigenetic modifications modulate DNA transcription through mechanisms such as DNA methylation [77], histone modifications [78], and non-coding RNA (ncRNA) regulation [79].

Among them, DNA methylation is the most extensively studied epigenetic mechanism, wherein a methyl group $\left(-\mathrm{CH}_{3}\right)$ from 
$S$-adenosylmethionine (SAM) is transferred to the 5-position of cytosines, in certain $\mathrm{CpG}$ dinucleotides, by a family of DNA methyltransferase enzymes (DNMTs). The DNMTs can be classified into three major types based on their different structures and functions, DNMT1, DNMT3a, and DNMT3b [77,80-82]. DNMT1 was identified as having a role in the maintenance of methylation during each cellular replication when DNA is duplicated [83]. DNMT3a and DNMT3b have de novo methylation ability, wherein new 5-methylcytosines are introduced in initially non-methylated genome sites $[84,85]$. In most cases, DNA methylation not only induces gene silencing [86], but also is related to the initiation of DNA replication [87], DNA mismatch repair [88] and inactivation of transposons [89].

Recently, more and more studies have discovered that CNS dysfunction may be potentially affected by DNA methylation. DNA methylation was associated with expression of neurotransmitters. In an in vitro study, hypermethylation of the excitatory amino acid transporter (EAAT2) promoter in glioma cells led to a deficiency in astroglial EAAT2 expression, which was related to the pathogenesis of CNS disorders with remarkable excitatory toxicity elements. Furthermore, the transcription of EAAT2 could be recovered by suppression of DNA methyltransferases [90]. Neurodegenerative diseases, such as Alzheimer's disease (AD) [91], Huntington's disease (HD) [92], and amyotrophic lateral sclerosis (ALS) [93], are regulated by DNA methylation. Meanwhile, psychiatric disorders have been associated with an abnormal DNA methylation status in brain [94-96].

Few reports have described abnormal DNA methylation induced by NPs. $\mathrm{SiO}_{2}$ NPs can reduce global DNA methylation levels and change the methylation status of the PARP-1 promoter in human keratinocytes (HaCat) [97,98]. Silver NPs had the ability to change DNA methylation as well [99]. In a recent study, DNA methylation status, regulated by DNMTs in the A549 cell line, could be altered by oxidative stress induced by $\mathrm{TiO}_{2}$ NPs [100]. As OS is a main mechanism of nanotoxicity, we hypothesize that $\mathrm{TiO}_{2}$ NPs might be able to alter DNA methylation status in the brain through an OS-mediated pathway. More studies are needed to further investigate the role of DNA methylation in $\mathrm{TiO}_{2}$ NPs-induced neurotoxicity.

\section{Conclusion}

$\mathrm{TiO}_{2}$ NPs possess unique characteristics due to their tiny size and are widely used in many fields. The rapid development of nanotechnology and widespread applications of products based on nanomaterials are possible causes of neurological disorders in humans. Therefore, numerous in vivo and in vitro studies have been conducted to assess the neurotoxicity of $\mathrm{TiO}_{2} \mathrm{NPs}$. However, the exact underlying mechanisms of $\mathrm{TiO}_{2}$ NPs-in- duced neurotoxicity are unclear. Through summarizing studies describing the neurotoxicity of $\mathrm{TiO}_{2} \mathrm{NPs}$, we found that these mechanisms mainly consisted of oxidative stress (OS), apoptosis, inflammatory responses, genotoxicity, and direct impairment of cell components. Meanwhile, other mechanisms, including disturbed distributions of trace elements, disrupted signaling pathways, dysregulated levels of neurotransmitters, and synaptic plasticity also contribute to the neurotoxicity of $\mathrm{TiO}_{2}$ NPs. Furthermore, recent studies implicated autophagy and DNA methylation as results of nanotoxicity. Therefore, we hypothesized that these two mechanisms could be potentially involved in the neurotoxicity of $\mathrm{TiO}_{2} \mathrm{NPs}$. Further studies are needed to test these hypotheses.

In summary, to fully understand the health threats to the brain posed by $\mathrm{TiO}_{2} \mathrm{NPs}$, and improve the bio-safety of $\mathrm{TiO}_{2}$ NPs-based products, every possible molecular mechanism of $\mathrm{TiO}_{2}$ NPs-induced neurotoxicity must be investigated comprehensively.

\section{Author contributions}

Bin Song collected and reviewed the data and drafted the manuscript. All authors helped in drafting the first version of the manuscript and in revisions. All authors read and approved the final manuscript.

\section{Acknowledgements}

This work was supported by the Science and Technology Foundation of the Health and Family Planning Commission of Guizhou province, China (gzwjkj2015-1-026), the National Natural Science Foundation of China (81550011), and the Natural Science Foundation of Guangdong Province of China (2015A030313299).

\section{References}

1. Chen, X.; Mao, S. S. Chem. Rev. 2007, 107, 2891-2959. doi:10.1021/cr0500535

2. Montazer, M.; Seifollahzadeh, S. Photochem. Photobiol. 2011, 87, 877-883. doi:10.1111/j.1751-1097.2011.00917.x

3. Adam, V.; Loyaux-Lawniczak, S.; Quaranta, G. Environ. Sci. Pollut. Res. 2015, 22, 11175-11192. doi:10.1007/s11356-015-4661-x

4. Shi, H.; Magaye, R.; Castranova, V.; Zhao, J. Part. Fibre Toxicol. 2013, 10, No. 15. doi:10.1186/1743-8977-10-15

5. Geraets, L.; Oomen, A. G.; Krystek, P.; Jacobsen, N. R.; Wallin, H.; Laurentie, M.; Verharen, H. W.; Brandon, E. F. A.; de Jong, W. H. Part. Fibre Toxicol. 2014, 11, 30. doi:10.1186/1743-8977-11-30

6. Disdier, C.; Devoy, J.; Cosnefroy, A.; Chalansonnet, M.; Herlin-Boime, N.; Brun, E.; Lund, A.; Mabondzo, A. Part. Fibre Toxicol. 2015, 12, 27. doi:10.1186/s12989-015-0102-8 
7. Pelclova, D.; Zdimal, V.; Fenclova, Z.; Vlckova, S.; Turci, F.; Corazzari, I.; Kacer, P.; Schwarz, J.; Zikova, N.; Makes, O.; Syslova, K.; Komarc, M.; Belacek, J.; Navratil, T.; Machajova, M.; Zakharov, S. Occup. Environ. Med. 2016, 73, 110-118. doi:10.1136/oemed-2015-103161

8. Song, B.; Liu, J.; Feng, X.; Wei, M.; Shao, L. Nanoscale Res. Lett. 2015, 10, 342. doi:10.1186/s11671-015-1042-9

9. Stern, S. T.; Adiseshaiah, P. P.; Crist, R. M. Part. Fibre Toxicol. 2012, 9, 20. doi:10.1186/1743-8977-9-20

10. Shyamasundar, S.; Ng, C. T.; Yung, L. Y. L.; Dheen, S. T.; Bay, B. H. Epigenomics 2015, 7, 395-411. doi:10.2217/epi.15.3

11. Stoccoro, A.; Karlsson, H. L.; Coppedè, F.; Migliore, L. Toxicology 2013, 313, 3-14. doi:10.1016/j.tox.2012.12.002

12. Mizushima, N.; Komatsu, M. Cell 2011, 147, 728-741. doi:10.1016/j.cell.2011.10.026

13. Jaenisch, R.; Bird, A. Nat. Genet. 2003, 33, 245-254. doi:10.1038/ng1089

14. Egger, G.; Liang, G.; Aparicio, A.; Jones, P. A. Nature 2004, 429, 457-463. doi:10.1038/nature02625

15. Armstrong, J. S.; Rajasekaran, M.; Chamulitrat, W.; Gatti, P.; Hellstrom, W. J.; Sikka, S. C. Free Radical Biol. Med. 1999, 26, 869-880. doi:10.1016/s0891-5849(98)00275-5

16. Starkov, A. A. Ann. N. Y. Acad. Sci. 2008, 1147, 37-52. doi:10.1196/annals.1427.015

17. Jaiswal, A. K. Free Radical Biol. Med. 2004, 36, 1199-1207. doi:10.1016/j.freeradbiomed.2004.02.074

18. Okuda, M.; Li, K.; Beard, M. R.; Showalter, L. A.; Scholle, F.; Lemon, S. M.; Weinman, S. A. Gastroenterology 2002, 122, 366-375. doi:10.1053/gast.2002.30983

19. Long, T. C.; Saleh, N.; Tilton, R. D.; Lowry, G. V.; Veronesi, B. Environ. Sci. Technol. 2006, 40, 4346-4352. doi:10.1021/es060589n

20. Long, T. C.; Tajuba, J.; Sama, P.; Saleh, N.; Swartz, C.; Parker, J.; Hester, S.; Lowry, G. V.; Veronesi, B. Environ. Health Perspect. 2007, 115, 1631-1637. doi:10.1289/ehp.10216

21. Wang, J.; Chen, C.; Liu, Y.; Jiao, F.; Li, W.; Lao, F.; Li, Y.; Li, B.; Ge, C.; Zhou, G.; Gao, Y.; Zhao, Y.; Chai, Z. Toxicol. Lett. 2008, 183, 72-80. doi:10.1016/j.toxlet.2008.10.001

22. Krawczyńska, A.; Dziendzikowska, K.; Gromadzka-Ostrowska, J.; Lankoff, A.; Herman, A. P.; Oczkowski, M.; Królikowski, T.; Wilczak, J.; Wojewódzka, M.; Kruszewski, M. Food Chem. Toxicol. 2015, 85, 96-105. doi:10.1016/j.fct.2015.08.005

23. Shrivastava, R.; Raza, S.; Yadav, A.; Kushwaha, P.; Flora, S. J. S. Drug Chem. Toxicol. 2014, 37, 336-347. doi:10.3109/01480545.2013.866134

24. Yin, J.; Kang, C.; Li, Y.; Li, Q.; Zhang, X.; Li, W. Toxicol. Res. (Cambridge, U. K.) 2014, 3, 367-374 doi:10.1039/c4tx00040d

25. Ma, L.; Liu, J.; Li, N.; Wang, J.; Duan, Y.; Yan, J.; Liu, H.; Wang, H.; Hong, F. Biomaterials 2010, 31, 99-105. doi:10.1016/j.biomaterials.2009.09.028

26. Cui, Y.; Chen, X.; Zhou, Z.; Lei, Y.; Ma, M.; Cao, R.; Sun, T.; Xu, J.; Huo, M.; Cao, R.; Wen, C.; Che, Y. Chemosphere 2014, 96, 99-104. doi:10.1016/j.chemosphere.2013.07.051

27. Block, M. L.; Zecca, L.; Hong, J.-S. Nat. Rev. Neurosci. 2007, 8, 57-69. doi:10.1038/nrn2038

28. Olson, J. K.; Miller, S. D. J. Immunol. 2004, 173, 3916-3924. doi:10.4049/jimmunol.173.6.3916
29. Su, M.; Sheng, L.; Zhao, X.; Wang, L.; Yu, X.; Hong, J.; Xu, B.; Liu, D.; Jiang, H.; Ze, X.; Zhu, Y.; Long, Y.; Zhou, J.; Cui, J.; Li, K.; Ze, Y.; Hong, F. Toxicol. Res. (Cambridge, U. K.) 2015, 4, 344-350. doi:10.1039/c4tx00106k

30. Ze, Y.; Sheng, L.; Zhao, X.; Hong, J.; Ze, X.; Yu, X.; Pan, X.; Lin, A.; Zhao, Y.; Zhang, C.; Zhou, Q.; Wang, L.; Hong, F. PLoS One 2014, 9, No. e92230. doi:10.1371/journal.pone.0092230

31. Ze, Y.; Zheng, L.; Zhao, X.; Gui, S.; Sang, X.; Su, J.; Guan, N.; Zhu, L.; Sheng, L.; Hu, R.; Cheng, J.; Cheng, Z.; Sun, Q.; Wang, L.; Hong, F. Chemosphere 2013, 92, 1183-1189. doi:10.1016/j.chemosphere.2013.01.094

32. Liu, Y.; Xu, Z.; Li, X. Brain Inj. 2013, 27, 934-939. doi:10.3109/02699052.2013.793401

33. Elmore, S. Toxicol. Pathol. 2007, 35, 495-516. doi:10.1080/01926230701320337

34. Wirawan, E.; Vande Walle, L.; Kersse, K.; Cornelis, S.; Claerhout, S.; Vanoverberghe, I.; Roelandt, R.; De Rycke, R.; Verspurten, J.; Declercq, W.; Agostinis, P.; Vanden Berghe, T.; Lippens, S.; Vandenabeele, P. Cell Death Dis. 2010, 1, No. e18. doi:10.1038/cddis.2009.16

35. Sheng, L.; Ze, Y.; Wang, L.; Yu, X.; Hong, J.; Zhao, X.; Ze, X.; Liu, D.; Xu, B.; Zhu, Y.; Long, Y.; Lin, A.; Zhang, C.; Zhao, Y.; Hong, F. J. Biomed. Mater. Res., Part A 2015, 103, 1141-1149. doi:10.1002/jbm.a.35263

36. Li, X.; Xu, S.; Zhang, Z.; Schluesener, H. J. Chin. Sci. Bull. 2009, 54, 3830-3836. doi:10.1007/s11434-009-0548-x

37. Lai, J. C. K.; Lai, M. B.; Jandhyam, S.; Dukhande, V. V.; Bhushan, A.; Daniels, C. K.; Leung, S. W. Int. J. Nanomed. 2008, 3, 533-545. doi:10.2147/IJN.S3234

38. Wilson, C. L.; Natarajan, V.; Hayward, S. L.; Khalimonchuk, O.; Kidambi, S. Nanoscale 2015, 7, 18477-18488. doi:10.1039/c5nr03646a

39. Coccini, T.; Grandi, S.; Lonati, D.; Locatelli, C.; De Simone, U. NeuroToxicology 2015, 48, 77-89. doi:10.1016/j.neuro.2015.03.006

40. Mao, Z.; Xu, B.; Ji, X.; Zhou, K.; Zhang, X.; Chen, M.; Han, X.; Tang, Q.; Wang, X.; Xia, Y. Nanoscale 2015, 7, 8466-8475. doi:10.1039/c5nr01448d

41. Ben Younes, N. R.; Amara, S.; Mrad, I.; Ben-Slama, I.; Jeljeli, M.; Omri, K.; El Ghoul, J.; El Mir, L.; Ben Rhouma, K.; Abdelmelek, H.; Sakly, M. Environ. Sci. Pollut. Res. 2015, 22, 8728-8737. doi:10.1007/s11356-014-4002-5

42. Golbamaki, N.; Rasulev, B.; Cassano, A.; Robinson, R. L. M.; Benfenati, E.; Leszczynski, J.; Cronin, M. T. D. Nanoscale 2015, 7, 2154-2198. doi:10.1039/c4nr06670g

43. El-Ghor, A. A.; Noshy, M. M.; Galal, A.; Mohamed, H. R. H. Toxicol. Sci. 2014, 142, 21-32. doi:10.1093/toxsci/kfu157

44. Kumar, S. S.; Shankar, B.; Sainis, F. B. Biochim. Biophys. Acta, Gen. Subj. 2004, 1672, 100-111. doi:10.1016/j.bbagen.2004.03.002

45. Zhang, Y.; Guan, L.; Wang, X.; Wen, T.; Xing, J.; Zhao, J. Free Radical Res. 2008, 42, 362-371. doi:10.1080/10715760801993076

46. Indo, H. P.; Davidson, M.; Yen, H.-C.; Suenaga, S.; Tomita, K.; Nishii, T.; Higuchi, M.; Koga, Y.; Ozawa, T.; Majima, H. J. Mitochondrion 2007, 7, 106-118. doi:10.1016/j.mito.2006.11.026

47. Kizaki, M.; Xian, M.; Sagawa, M.; Ikeda, Y. Curr. Pharm. Biotechnol. 2006, 7, 323-329. doi:10.2174/138920106778521541 
48. Huerta-García, E.; Pérez-Arizti, J. A.; Márquez-Ramírez, S. G.; Delgado-Buenrostro, N. L.; Chirino, Y. I.; Iglesias, G. G.; López-Marure, R. Free Radical Biol. Med. 2014, 73, 84-94. doi:10.1016/j.freeradbiomed.2014.04.026

49. Wang, J.; Liu, Y.; Jiao, F.; Lao, F.; Li, W.; Gu, Y.; Li, Y.; Ge, C.; Zhou, G.; Li, B.; Zhao, Y.; Chai, Z.; Chen, C. Toxicology 2008, 254, 82-90. doi:10.1016/j.tox.2008.09.014

50. Shimizu, M.; Tainaka, H.; Oba, T.; Mizuo, K.; Umezawa, M.; Takeda, K. Part. Fibre Toxicol. 2009, 6, No. 20. doi:10.1186/1743-8977-6-20

51. Liu, S.; Xu, L.; Zhang, T.; Ren, G.; Yang, Z. Toxicology 2010, 267, 172-177. doi:10.1016/j.tox.2009.11.012

52. Márquez-Ramírez, S. G.; Delgado-Buenrostro, N. L.; Chirino, Y. I.; Iglesias, G. G.; López-Marure, R. Toxicology 2012, 302, 146-156. doi:10.1016/j.tox.2012.09.005

53. Valdiglesias, V.; Costa, C.; Sharma, V.; Kiliç, G.; Pásaro, E.; Teixeira, J. P.; Dhawan, A.; Laffon, B. Food Chem. Toxicol. 2013, 57, 352-361. doi:10.1016/j.fct.2013.04.010

54. Hu, R.; Zheng, L.; Zhang, T.; Gao, G.; Cui, Y.; Cheng, Z.; Cheng, J.; Hong, M.; Tang, M.; Hong, F. J. Hazard. Mater. 2011, 191, 32-40. doi:10.1016/j.jhazmat.2011.04.027

55. Meena, R.; Kumar, S.; Paulraj, R. J. Nanopart. Res. 2015, 17, 49. doi:10.1007/s11051-015-2868-x

56. Hong, F.; Sheng, L.; Ze, Y.; Hong, J.; Zhou, Y.; Wang, L.; Liu, D.; Yu, X.; Xu, B.; Zhao, X.; Ze, X. Biomaterials 2015, 53, 76-85. doi:10.1016/j.biomaterials.2015.02.067

57. Ze, Y.; Sheng, L.; Zhao, X.; Ze, X.; Wang, X.; Zhou, Q.; Liu, J.; Yuan, Y.; Gui, S.; Sang, X.; Sun, Q.; Hong, J.; Yu, X.; Wang, L.; Li, B.; Hong, F. J. Hazard. Mater. 2014, 264, 219-229. doi:10.1016/j.jhazmat.2013.10.072

58. Mohammadipour, A.; Fazel, A.; Haghir, H.; Motejaded, F.; Rafatpanah, H.; Zabihi, H.; Hosseini, M.; Bideskan, A. E. Environ. Toxicol. Pharmacol. 2014, 37, 617-625. doi:10.1016/j.etap.2014.01.014

59. Takahashi, Y.; Mizuo, K.; Shinkai, Y.; Oshio, S.; Takeda, K. J. Toxicol. Sci. 2010, 35, 749-756. doi:10.2131/jts.35.749

60. Umezawa, M.; Tainaka, H.; Kawashima, N.; Shimizu, M.; Takeda, K. J. Toxicol. Sci. 2012, 37, 1247-1252. doi:10.2131/jts.37.1247

61. Hu, R.; Gong, X.; Duan, Y.; Li, N.; Che, Y.; Cui, Y.; Zhou, M.; Liu, C.; Wang, H.; Hong, F. Biomaterials 2010, 31, 8043-8050. doi:10.1016/j.biomaterials.2010.07.011

62. Gao, X.; Yin, S.; Tang, M.; Chen, J.; Yang, Z.; Zhang, W.; Chen, L.; Yang, B.; Li, Z.; Zha, Y.; Ruan, D.; Wang, M. Biol. Trace Elem. Res. 2011, 143, 1616-1628. doi:10.1007/s12011-011-8990-4

63. Wu, J.; Sun, J.; Xue, Y. Toxicol. Lett. 2010, 199, 269-276. doi:10.1016/j.toxlet.2010.09.009

64. Levine, B.; Kroemer, G. Cell 2008, 132, 27-42. doi:10.1016/j.cell.2007.12.018

65. Mizushima, N.; Levine, B.; Cuervo, A. M.; Klionsky, D. J. Nature 2008, 451, 1069-1075. doi:10.1038/nature06639

66. Cohignac, V.; Landry, M. J.; Boczkowski, J.; Lanone, S. Nanomaterials 2014, 4, 548-582. doi:10.3390/nano4030548

67. Li, J. J.; Hartono, D.; Ong, C.-N.; Bay, B.-H.; Yung, L.-Y. L. Biomaterials 2010, 31, 5996-6003. doi:10.1016/j.biomaterials.2010.04.014

68. Khan, M. I.; Mohammad, A.; Patil, G.; Naqvi, S. A. H.; Chauhan, L. K. S.; Ahmad, I. Biomaterials 2012, 33, 1477-1488. doi:10.1016/j.biomaterials.2011.10.080
69. Hussain, S.; Al-Nsour, F.; Rice, A. B.; Marshburn, J.; Yingling, B.; Ji, Z. X.; Zink, J. I.; Walker, N. J.; Garantziotis, S. ACS Nano 2012, 6, 5820-5829. doi:10.1021/nn302235u

70. Sun, T.; Yan, Y.; Zhao, Y.; Guo, F.; Jiang, C. PLoS One 2012, 7, No. e43442. doi:10.1371/journal.pone.0043442

71. Yu, Y.; Duan, J.; Yu, Y.; Li, Y.; Liu, X.; Zhou, X.; Ho, K.-F.; Tian, L.; Sun, Z. J. Hazard. Mater. 2014, 270, 176-186. doi:10.1016/j.jhazmat.2014.01.028

72. Yu, K.-N.; Yoon, T.-J.; Minai-Tehrani, A.; Kim, J.-E.; Park, S. J.; Jeong, M. S.; Ha, S.-W.; Lee, J.-K.; Kim, J. S.; Cho, M.-H. Toxicol. In Vitro 2013, 27, 1187-1195. doi:10.1016/j.tiv.2013.02.010

73. Lee, Y.-H.; Cheng, F.-Y.; Chiu, H.-W.; Tsai, J.-C.; Fang, C.-Y.; Chen, C.-W.; Wang, Y.-J. Biomaterials 2014, 35, 4706-4715. doi:10.1016/j.biomaterials.2014.02.021

74. Yu, K.-N.; Chang, S.-H.; Park, S. J.; Lim, J.; Lee, J.; Yoon, T.-J.; Kim, J.-S.; Cho, M.-H. PLoS One 2015, 10, No. e0131208. doi:10.1371/journal.pone.0131208

75. Zhao, Y.; Howe, J. L. C.; Yu, Z.; Leong, D. T.; Chu, J. J. H.; Loo, J. S. C.; Ng, K. W. Small 2013, 9, 387-392. doi:10.1002/smll.201201363

76. Qureshi, I. A.; Mehler, M. F. Mol. Aspects Med. 2013, 34, 875-882. doi:10.1016/j.mam.2012.06.011

77. Bird, A. P. Nature 1986, 321, 209-213. doi:10.1038/321209a0

78. Strahl, B. D.; Allis, C. D. Nature 2000, 403, 41-45. doi:10.1038/47412

79. Mattick, J. S.; Makunin, I. V. Hum. Mol. Genet. 2006, 15 (Suppl. 1), R17-R29. doi:10.1093/hmg/ddl046

80. Robertson, K. D.; Uzvolgyi, E.; Liang, G.; Talmadge, C.; Sumegi, J.; Gonzales, F. A.; Jones, P. A. Nucleic Acids Res. 1999, 27, 2291-2298. doi:10.1093/nar/27.11.2291

81. Fujii, S.; Wang, A. H.-J.; van der Marel, G.; van Boom, J. H.; Rich, A. Nucleic Acids Res. 1982, 10, 7879-7892. doi:10.1093/nar/10.23.7879

82. Chiang, P. K.; Gordon, R. K.; Tal, J.; Zeng, G. C.; Doctor, B. P.; Pardhasaradhi, K.; McCann, P. P. FASEB J. 1996, 10, 471-480.

83. Robert, M.-F.; Morin, S.; Beaulieu, N.; Gauthier, F.; Chute, I. C.; Barsalou, A.; MacLeod, A. R. Nat. Genet. 2002, 33, 61-65. doi:10.1038/ng1068

84. Okano, M.; Bell, D. W.; Haber, D. A.; Li, E. Cell 1999, 99, 247-257. doi:10.1016/s0092-8674(00)81656-6

85. Bachman, K. E.; Rountree, M. R.; Baylin, S. B. J. Biol. Chem. 2001, 276, 32282-32287. doi:10.1074/jbc.M104661200

86. Herman, J. G.; Latif, F.; Weng, Y.; Lerman, M. I.; Zbar, B.; Liu, S.; Samid, D.; Duan, D. S.; Gnarra, J. R.; Linehan, W. M. Proc. Natl. Acad. Sci. U. S. A. 1994, 91, 9700-9704. doi:10.1073/pnas.91.21.9700

87. Schübeler, D.; Lorincz, M. C.; Cimbora, D. M.; Telling, A.; Feng, Y.-Q.; Bouhassira, E. E.; Groudine, M. Mol. Cell. Biol. 2000, 20, 9103-9112. doi:10.1128/mcb.20.24.9103-9112.2000

88. Hare, J. T.; Taylor, J. H. Proc. Natl. Acad. Sci. U. S. A. 1985, 82, 7350-7354. doi:10.1073/pnas.82.21.7350

89. Reinders, J.; Wulff, B. B. H.; Mirouze, M.; Marí-Ordóñez, A.; Dapp, M.; Rozhon, W.; Bucher, E.; Theiler, G.; Paszkowski, J. Genes Dev. 2009, 23, 939-950. doi:10.1101/gad.524609

90. Zschocke, J.; Allritz, C.; Engele, J.; Rein, T. Glia 2007, 55, 663-674 doi:10.1002/glia.20497 
91. De Jager, P. L.; Srivastava, G.; Lunnon, K.; Burgess, J.; Schalkwyk, L. C.; Yu, L.; Eaton, M. L.; Keenan, B. T.; Ernst, J.; McCabe, C.; Tang, A.; Raj, T.; Replogle, J.; Brodeur, W.; Gabriel, S.; Chai, H. S.; Younkin, C.; Younkin, S. G.; Zou, F.; Szyf, M.;

Epstein, C. B.; Schneider, J. A.; Bernstein, B. E.; Meissner, A.; Ertekin-Taner, N.; Chibnik, L. B.; Kellis, M.; Mill, J.; Bennett, D. A. Nat. Neurosci. 2014, 17, 1156-1163. doi:10.1038/nn.3786

92. Ng, C. W.; Yildirim, F.; Yap, Y. S.; Dalin, S.; Matthews, B. J.; Velez, P. J.; Labadorf, A.; Housman, D. E.; Fraenkel, E. Proc. Natl. Acad. Sci. U. S. A. 2013, 110, 2354-2359. doi:10.1073/pnas.1221292110

93. Wong, M.; Gertz, B.; Chestnut, B. A.; Martin, L. J. Front. Cell. Neurosci. 2013, 7, No. 279. doi:10.3389/fncel.2013.00279

94. Mill, J.; Tang, T.; Kaminsky, Z.; Khare, T.; Yazdanpanah, S.; Bouchard, L.; Jia, P.; Assadzadeh, A.; Flanagan, J.; Schumacher, A.; Wang, S.-C.; Petronis, A. Am. J. Hum. Genet. 2008, 82, 696-711. doi:10.1016/j.ajhg.2008.01.008

95. Chen, C.; Zhang, C.; Cheng, L.; Reilly, J. L.; Bishop, J. R.; Sweeney, J. A.; Chen, H.-Y.; Gershon, E. S.; Liu, C. Bipolar Disord. 2014, 16, 790-799. doi:10.1111/bdi.12255

96. Haghighi, F.; Xin, Y.; Chanrion, B.; O'Donnell, A. H.; Ge, Y.; Dwork, A. J.; Arango, V.; Mann, J. J. Dialogues Clin. Neurosci 2014, 16, 430-438.

97. Gong, C.; Tao, G.; Yang, L.; Liu, J.; Liu, Q.; Li, W.; Zhuang, Z. Toxicol. Lett. 2012, 209, 264-269. doi:10.1016/j.toxlet.2012.01.007

98. Gong, C.; Tao, G.; Yang, L.; Liu, J.; Liu, Q.; Zhuang, Z. Biochem. Biophys. Res. Commun. 2010, 397, 397-400. doi:10.1016/j.bbrc.2010.05.076

99. Zhang, X.-F.; Park, J.-H.; Choi, Y.-J.; Kang, M.-H.; Gurunathan, S.; Kim, J.-H. Int. J. Nanomed. 2015, 10, 7057-7071. doi:10.2147/ijn.s95694

100.Bai, W.; Chen, Y.; Gao, A. Int. J. Nanomed. 2015, 10, 5561-5569. doi:10.2147/ijn.s88059

\section{License and Terms}

This is an Open Access article under the terms of the Creative Commons Attribution License (http://creativecommons.org/licenses/by/2.0), which permits unrestricted use, distribution, and reproduction in any medium, provided the original work is properly cited.

The license is subject to the Beilstein Journal of Nanotechnology terms and conditions: (http://www.beilstein-journals.org/bjnano)

The definitive version of this article is the electronic one which can be found at: $\underline{\text { doi:10.3762/bjnano.7.57 }}$ 